\title{
SOCIAL CHANGE OR SOCIAL EVOLUTION?
}

\section{ARGUMENTS FOR RETAINING THE CONCEPT OF SOCIAL PROGRESS IN THE SOCIOLOGICAL THEORY OF EVOLUTION}

PÉTER GEDEON ${ }^{l}$

\begin{abstract}
Sociological theory adapted an evolutionary theoretical framework for understanding social change in the nineteenth century. Later on, the evolutionary approach was challenged, modified or rejected. This paper examines the controversy between anti-evolutionary and neoevolutionary theories. Antievolutionary theories attack the concept of social progress, while neo-evolutionary theories defend it. At present, it seems, macrosociological theory has abandoned the concept of social progress. This paper argues that from an analytical perspective there is no compelling argument to do this. Sociological theory may retain the concept of social change linked to evolutionary theory if in the light of criticisms it redefines it.
\end{abstract}

KEYWORDS: social progress, social evolution, evolutionary universals, specific versus general evolution, unintended consequences of human action

\section{INTRODUCTION}

Theories of social evolution make an attempt to conceptualize social change. Any theory of social evolution presumes the concept of social change; however, the concept of social change does not presume that of social evolution: social

1 Professor at the Department of Comparative and Institutional Economics, Corvinus University of Budapest; e-mail: pgedeon@uni-corvinus.hu . The author is grateful to Péter Somlai for his comments on an earlier version of this paper, and to OTKA for its financial support (T-037764). 
change can also be dealt with within a non-evolutionary conceptual framework. ${ }^{2}$ Acceptance and/or denial of the idea of social evolution also changes from time to time. The historical fluctuations in the interpretations of social change are closely related to changes in ideologies and the social processes behind them. ${ }^{3}$ This paper is not about the relationship of social theory and ideologies, nor about issues discussed in the sociology of knowledge: instead, it is about the analytical issue whether the criticism of evolutionary theories is acceptable. To be more specific, I address the question whether it is true that the theory of social evolution can only be saved if we abandon the idea of social progress. At present, it seems to be a majority view in sociology that the theory of social evolution should be separated from the idea of social progress. ${ }^{4}$

I argue, to some extent against the wind, that the outcomes of the theoretical controversy about the relationship between social evolution and social progress cannot be considered a forgone conclusion. Consequently, the present majority view has a lot to do with changes in modern societies, and with the ideological context (not just the analytical content) of these concepts.

The concept of social progress and that of social evolution are not the same. The criticism of the concept of social progress in general is not identical with criticism of the idea of social evolution. Since in this paper I focus on theories of social evolution, I do not discuss discourses about the idea of social progress presented either in the history of philosophy or in postmodern theories because they stop prior to, or go beyond, the domain of macrosociological theory. In this paper I first reproduce critiques of evolutionary theory. I then deal with the arguments of the critics of the criticisms of evolutionary theory. Finally, I conclude.

2 Mandelbaum argues in a similar vein about the relationship of social change to social progress. "The concept of development always involves the concept of change. However, not every type of change is an instance of development. What strikes us as a random, patternless change is not regarded as an instance of development. Furthermore, we do not take all patterned changes - for example, the changing of traffic lights from red to green to red to green - as instances of development." (Mandelbaum 1971: 43)

3 This connection is discussed in Sárkány and Somlai (2003).

4 "Contemporary social sciences put the notion of 'social progress' into the dustbin of ideas, neo-neoevolutionary sociology got rid of the assumption that history has got a direction and consequently, it freed itself from the idea that social change is centered around modernization." Sárkány and Somlai (2003: 22) 


\section{WHAT IS WRONG WITH THE THEORY OF SOCIAL EVOLUTION?}

Theories of social evolution have incited two kinds of critiques; one radical, and the other moderate. Radical critics of the theory of social evolution raise methodological issues with the theory of social evolution. They argue that social change cannot be understood through evolutionary theory, therefore the latter is not needed. The theory of social evolution is nothing else but a pre-scientific metaphor applied to socio-historical material. This metaphor is based on an essentialist argument that contrasting essence to appearance duplicates social reality. Evolutionary theory constructs a logical scheme of historical change that is different from real, empirical history. Consequently, evolutionary theory is unable to grasp real historical change, but instead generates a circular and tautological scheme of concepts that do not support the hypotheses behind the theory.

Radical critics also attack evolutionary theory because they do not accept the concept of social progress. Since they identify the theory of evolution with the theory of social progress, they want to get rid of the former because they find untenable the latter.

The theory of social evolution is also criticized for its bias toward Western social development. The concept of social progress assumes a dichotomy of traditional and modern societies with the conclusion that modern societies are more developed than traditional ones. Since modernity emerged in Western societies, this argument puts Western capitalism at the center of the analysis and uses it as a benchmark for understanding traditional societies. The theory's built-in bias makes it unacceptable.

Moderate criticism differs from radical criticism because it seeks to separate the concept of evolution from that of progress. According to this position, the idea of social progress must be rejected, but the evolutionary approach should be preserved. Let me now spell out these criticisms in a more detailed way.

\section{Societies are ordered in a developmental sequence}

The theory of social evolution specifies different types of society and inserts them into a historical order that represents a developmental sequence from the perspective of a specific predefined criterion. This sequence is the ordering of static images and does not reflect real historical processes. There is no such thing as a comprehensive social evolutionary process; there exist only particular 
and different societies. The unity of the developmental process that connects the different stages of social development is not created by history but the logic of classification: evolutionary theory does not extract the logic of development of history, but instead it inserts this logic into history (Nisbet 1969: 196-197, 294). The analytically constructed order of the historical stages of social development does not reflect real historical processes of development, because these processes do not exist.

"The real objection is to genetic continuity: to the fixed notion within the conventional wisdom of social science that one change necessarily engenders another, that one 'stage' of developmental change produces the next stage, just as one stage of growth does in the organism. There is not the slightest empirical evidence for this when we confine attention to the concrete area and to finite time." (Nisbet 1969: 290-291)

The analytical scheme of social evolution fakes explanations of historical change by interpreting any particular social process as a stage of general social evolution. We shall not understand the real changes of a society if we insert them into the process of comprehensive social development; on the contrary, the specific historical changes of a given society should be explained in light of the particular historical changes of that society. For example, we will be able to understand feudal societies only if we look at the specific historical context and embeddedness of these societies. Evolutionary theory interprets feudalism as a step leading to capitalism, therefore tries to explain feudal society from the perspective of an abstract analytical scheme that assumes away the historical conditions of its development - argues Giddens. ${ }^{5}$ If we apply the abstract developmental scheme of social evolution to real historical change we will lose the opportunity to understand the specificity of particular historical processes and societies.

"...the many individual strands of continuity that must be traced if we are to understand what actually happened in the human past, form an indefinitely complex network. In this network, no event is likely to have a place in only one of the crisscrossing lines of causal connection,

5 "The first danger, unilineal compression, means the tendency of evolutionary thinkers to compress general into specific evolution. Thus feudalism precedes capitalism in Europe and is the social nexus from which capitalism develops. It is therefore, in one sense at least, the necessary forerunner of capitalism. Is feudalism, then, a general 'stage' in the evolution of capitalism? Surely not, although there are versions of Marxism, and other schools of social though also, that would have it thus." (Giddens 1984: 239) 
and it could therefore be extremely misleading to view specific events solely in terms of the positions which they occupied in one among these strands." (Mandelbaum 1971: 133-134)

The differences among societies cannot be explained within the framework of a unified and universal development. Most importantly, the distinction between traditional and modern societies cannot be dealt with using an evolutionary theoretical framework that defines social evolution as a process of social differentiation.

"...there is certainly no doubt that two ages which are separated by a substantial period of time within a common area reveal differentness. It may indeed be possible to contrast the twentieth century with the twelfth in terms of the familiar logical continuum of Gemeinschaft and Gesellschaft, which we find in one form or other in all of the major sociologists. But differentness does not argue the existence of a uniting process, endemic, constitutive, genetic, and uniform, called differentiation." (Nisbet 1969: 287)

Any standard chosen as a criterion of progress must abstract away from specific historical time and space; consequently, it must abstract away from the real mechanism of social change. No evolutionary theory of stages of social development can reflect on the mechanisms of historical change, as Giddens also argues (1984).

"From Comte and Spencer onwards, evolutionary thinkers have referred to increasing complexity, differentiation and so on. Of course, 'evolution' could be used just to refer to such progression, abstracted from time and space. It may be justifiable to say, for example, that small, oral cultures are at one end of a continuum of energy consumption and distribution (or time-space distanciation), with the modern, industrialized societies at the other. There is no difficulty, either, in sustaining the claim that certain technical developments, or forms of social organization, are prerequisites to others. 'Evolution' in this sense is uncontentious as a concept. But to use 'evolution' in this way is not to explain anything about social change and does not meet the criterion of having a reasonably close affinity to biological evolution." (Giddens 1984: 232) 
Nisbet represents the radical, while Giddens represents the moderate criticism of evolutionary theory. Nisbet rejects the concept of social evolution; Giddens does not, although Giddens shares Nisbet's ideas about the abstract nature of evolutionary theory. Giddens does not want to throw away evolutionary theory, but attributes limited use to it.

Theories of social evolution are problematic, because their scheme of development is based on a standard of progress that is external to history, as Mandelbaum also argues. Where does this standard come from? Mandelbaum points out that the theoretical source of this standard is a presumption about human nature:

“...a belief in progress is not established through history, but it is brought to history. This should have been abundantly clear in the progressivist views and the social criticism of Mill, Arnold, and Huxley. It was also clear in the self-realizationism of Fichte and Green. It was even true, as we have seen, of the organicism of Comte, of Hegel, and of Marx, whose standards of what constitutes social well-being were not actually deduced from history, but were critically applied to it. But what, one might then ask, could be the source of such standards?... these standards have a basis in the specific propensities, interests, and needs which are basic in human nature." (Mandelbaum 1971: 267)

\section{The concepts of evolutionary theory are universal and therefore timeless}

Theories of social evolution that trace back the phenomena of historical change to the essence of deep social structures pursue a research strategy that aims at the discovery of the structural invariants hiding behind social phenomena. Nisbet thinks that it is a wrong approach to research that asks the wrong questions that lead to the wrong answers, and claims that variables cannot be described by constants (Nisbet 1969: 296). Is it possible to describe something that changes in time with concepts that are constant in time? Can finite and specific historical changes be explained using infinite non-specific non-historical concepts? Nisbet answers no (Nisbet 1969: 262). Universal, timeless concepts cannot grasp a historically changing and unique reality. The enquiry of social change requires specific concepts that also change in time. 
"Instead of assuming, charting, graphing, and searching for timeless structural constants that are supposedly involved in all modes of change, we may ask the question, what are the conditions under which actual social change takes place in the history of a given institution or given mode of social behavior or cultural area?" (Nisbet 1969: 275)

Boudon formulates a moderate critique of Nisbet's radical approach. Subsuming history under analytical constructions results in the formation of categories of ideal types. By definition, ideal types do not have empirical content, therefore ideal types of societies cannot represent a historical sequence. Ideal types of societies do not contain the empirical elements of the historical transformations of societies.

"In short, the theories of change fail when they are taken for what they cannot be taken to be, when they are considered as similar to physical theories leading to empirical predictions, rather than as idealized models." (Boudon 1983: 158)

Boudon does think that it makes sense to set up theoretical constructions, and finds it false to apply these directly to historical material:

"In the same fashion, classical typologies such as Redfield's, Tönnies', or Parsons' are very useful provided they are interpreted as constructs which as such never literally apply to the social reality, but which must rather be considered as general mental guides, as sources of inspiration for the building of theories proper.

Yet, interestingly enough, there is a general trend toward a realistic interpretation of such typologies. Instead of being taken as ideal - to use Weber's language - they are taken as real." (Boudon 1983: 157)

\section{History has direction}

To assume that history evolves progressively is prophecy, not science, says Nisbet. ${ }^{6}$ Evolutionary theory interprets progress as the unfolding of essential

6 "It is the assumed directionality of social change that accounts for the widespread confusion today between scientific prediction and prophecy." (Nisbet 1969: 286) 
social characteristics in time. This development has a direction that can be understood from the analysis of social structures. Connecting social change to the historical unfolding of a more or less hidden social essence is nothing more than applying a biological metaphor to society, argues Nisbet. This metaphor contains the analogy between social change and the growth-processes of the individual (1969: 166). It may establish a connection between functionalism and evolutionary thinking, claims Giddens.

"Organic metaphors have often provided the relation between the two. A plant or an organism contains within itself a trajectory of growth, an unfolding of latent potentialities. Change here is understood as governed by the mechanisms involved in such unfolding, with societies being regarded as clearly bounded unities. External conditions are held to accentuate or hold back processes of growth, but they are really a background against which the mechanisms of change operate." (Giddens 1984: 229)

The metaphor of organic growth concerns the unfolding of structurally given essence as the potential of a subject for growth in time. This metaphor hides the tension between the synchronic nature of functional explanation and the diachronic nature of causal explanation. That is why evolutionary theory may represent social change as a unified and immanent process. However, goes the criticism, social change is not a unified and immanent process. Societies that according to evolutionary theory should follow one another in time in reality may exist simultaneously.

External effects on the changes of societies are important. Societies that constitute the external environment for each other do influence each other. ${ }^{8}$ These external effects have imposed changes on societies through cultural diffusion, military occupation or emulation (Mandelbaum 1971: 133). What is

7 "In talking of time-space edges I want to emphasise the significance of the simultaneous existence of types of society in episodic transitions. If we take an evolutionary view of history, we tend to think of societal change in terms of 'stages', in which one type of society is supplanted by another, and so forth. But the emergence of class-divided societies, for example, did not eliminate tribal societies from the world. Industrial capitalism has existed, and still exists, in conjunction with various other types of society (including, now, socialism), however strong its tendency to corrode or to absorb them. Time-space edges refer to the forms of contact - and often of interdependence - between different structural types of society. These are edges of potential or actual social transformation, the often unstable intersections between different modes of societal organisation." (Giddens 1981: 23)

8 “...the conception of history as a process of autonomous self-development takes inadequate account of the possibility of significant external influences upon any social order. These external influences may take a variety of forms." (Mandelbaum 1971: 132) 
more, the idea of unified history may be accepted only if it covers the changes of all societies that exist or have existed in history, but this is impossible. Human history is not a "world-growth story", claims Giddens referring to Gellner (Giddens 1984: 237). The application of the evolutionary paradigm brings with itself a process of historical selection. Some societies lie within its application, others that do not are considered to be unimportant and fall out of it. ${ }^{9}$

The idea of a unified history contains a logical fallacy that is called the retrospective fallacy by Mandelbaum. The analyst who stands at the endpoint of a historical process with hindsight tends to interpret it as a process that realizes this endpoint as its destiny. The retrospective fallacy leads to a teleological and deterministic interpretation of history (Mandelbaum 1971: 134). An analyst captured by this fallacy loses the concept of historical alternatives.

"The retrospective fallacy is a fallacy because it rests on the fact that, when we have learned the actual outcome of a series of events, we tend to forget that other conclusions might have been possible: we ascribe a privileged position to that outcome and we view all earlier events as if they had been controlled by it." (Mandelbaum 1971: 134-135)

If we get rid of the retrospective fallacy, we escape the vicious circle of an argument that explains the sequence of particular historical events with a general theory of history that we have constructed only on the basis of the occurrence of these particular events. ${ }^{10}$

The theory of social evolution identifies the directionality of history as a progress moving from traditional to modern society. Traditional societies qualify as underdeveloped, while modern societies qualify as developed societies. The content of this progress may be specified by different representatives of evolutionary theory in a different way. Progress may mean the development of technology, the processes of industrialization, secularization, individualization, rationalization, democratization, etc. In sociological theory, social progress

9 "those who look upon human history as representing a single developmental process can be justly accused of not being able to find a place within that process for much that has occurred in the human past. This is not merely that details are omitted from consideration; the conception of a single developmental process does not permit one to view large tracts of the past as having any genuine historical significance at all." (Mandelbaum 1971: 130)

10 "Once one recognizes the difference between tracing the connections of a series of historical events in the order in which they developed, and viewing them retrospectively only, it is not possible to regard long-term changes as providing a basis on which to understand the specific events which actually occurred: the whole with respect to which these specific events are supposedly to be interpreted actually exists only because of the successive parts which it is alleged to explain." (Mandelbaum 1971: 136) 
is understood as a process of social differentiation and the growth of social complexity (Nisbet 1969: 191).

The values chosen as the criteria for social progress are problematic, argue the critics. The chosen standards (such as technological development, changes in energy consumption, etc.) refer not to society as a whole, but to specific social domains and subsystems; consequently, on the basis of these standards societies as wholes cannot be ordered or ranked as developed or underdeveloped.

Modern societies are more developed from the perspective of technological progress than traditional societies, but they also create social anomies that do not exist in traditional societies. So, can we say that modern societies in general are more developed than traditional societies? If the answer is yes, we either abstract away from those social relations that are not reflected in the standard of development we use, or we assume that the qualitative differences of social spheres can be compared and added up on a quantitative basis; that is, that the social surplus from technological progress is greater than the social losses related to social anomies.

The other problem is that certain standards of social development are controversial. How can the notion of social complexity as a standard of social progress be applied to the dichotomy of traditional versus modern society? The social relations of traditional societies can be more complex than those of modern societies. In this case, the chosen standard may not work. ${ }^{11}$ If different societies are ranked in a different way along different values or standards of development, we cannot talk about a comprehensive process of social evolution.

The theory of social evolution cannot be linked to the concept of social progress also for the reason that social development combines progress with regress, evolution with devolution..$^{12}$

Finally, critics point out that the dichotomy of traditional versus modern society is an ethnocentric ideological construct with the function of justifying Western social development. The theory of evolution is not the scientific

11 '...there is good reason to distrust the terms 'simple' and 'complex' as applied to classifying societies. Many 'primitive societies' have very complex modes of kinship organisation, and all possess languages of a structurally differentiated kind." (Giddens 1981: 90)

12 "Once this is granted, the supposition that mankind is inherently progressive will lose its plausibility. Whatever standard of progress we accept, it will assuredly not be true that we shall find all societies exhibiting progress. Even with respect to the actual history of any one society, it is not likely that we shall find that there has been only one directional tendency throughout the entire course of its history. What we may more reasonably expect is that, whatever standard we choose to apply, there have been times at which that society has progressed, and other times during which it has regressed; and there may be stretches of time during which there were no significant changes with respect to the particular criteria by means of which we estimate progress." (Mandelbaum 1971: 267) 
reconstruction of historical change of societies but the ideological legitimation of the modern capitalist society that came into existence in the West (Nisbet 1969: 190-191, 223). However, Giddens, representing the moderate critics of evolutionary theory, does not accept that there is an analytical connection between evolutionary theory and ethnocentrism.

“...evolutionary theories are highly prone to merge 'progression' with 'progress' because of ethnocentric assumptions which, while probably not logically implied in evolutionism, are very difficult in practice to avoid." (Giddens 1984: 232-233)

\section{Social progress is inevitable}

If social evolution is an immanent, teleological process, it must also be necessary that is unavoidable. Critics say that this thesis is false: historical necessity does not exist.

"Plainly, there is no necessity in any pattern of change if our attention is fixed, not upon the wholes and universals of social evolutionary theoretical interest, but instead upon the social behavior of human beings in time and place." (Nisbet 1969: 294)

History cannot be interpreted on the basis of developmental laws. Laws describe universally correct relationships among variables under well-specified conditions. The theory of social evolution does not distinguish between general law and its conditional application to history, but conflates the two and attributes logical necessities to historical processes. ${ }^{13}$ From this it follows that the law of social progress cannot tolerate deviations from the law. If in reality these deviations still emerge, the theory labels them abnormalities outside the investigation. The law of social progress is based on the assumption that the conditions of social change are identical for different societies. This assumption is unrealistic. On the other hand, if we understand that the conditions of social change are different for different societies, we also understand that these changes

13 "...functional laws are always conditional with respect to their application, although they are categorical with respect to the relationships which they formulate, whereas directional laws are categorical with respect to their applications, as well as with respect to the sequential relationships which they affirm." (Mandelbaum 1971: 120) 
cannot be inserted into one comprehensive process and cannot be explained using unconditional laws of progress (Mandelbaum 1971: 120-126).

\section{Social change is the act of a social subject}

If social change is an immanent and teleological process of social progress, it has to have a subject that unfolds it. Critics say that a subject like this does not exist. The social subject of social evolution is an analytical construction that does not have a reference point in reality. The claim that a more developed society is a differentiated version of an underdeveloped society assumes that society is a unified actor in history; that is, that society is the unit of evolution. In reality, societies are different. A unified subject of social progress does not exist, and a unified history does not exist either (Giddens 1984: 237). The real subject of social change is the individual, not society, civilization, culture, etc. (Giddens 1981: 21-22).

\section{Social evolution is based on adaptation}

Evolutionary theories do not answer questions about the mechanism of social evolution, say critics. On the basis of an analogy with biological evolution, the theory of social evolution refers to adaptation as a mechanism of social evolution. However, adaptation cannot be that mechanism, argues Giddens. Linking social change to the adaption of societies to their environment is a functional and not a causal explanation, therefore it does not explain the causes of change. Also, adaptation is not the motivational factor for individuals whose actions result in social change. This concept is thus lacking a microfoundation. To sum up, adaption is the wrong concept. The statement that societies have survived because they have adapted well to their environment is an explanation that also calls for explanation (Giddens 1981: 21). Explaining the survival of a society with adaptation is a tautology. What is more, it is misleading because it presents a functional relationship as a causal one. The potential of societies to produce and reproduce their material existence is an important condition of the survival of social institutions but it does not explain the emergence of these institutions, or their specific characteristics (Giddens 1984: 235-236).

Theories of social evolution unnecessarily broaden the concept of adaptation by extending it to adaptation to other societies and not just to nature. This 
broadening of the concept of adaptation makes it empty and useless (Giddens 1984: 234-235).

Finally, since evolutionary theories try to explain why societies go through a process of constant adaptation that may lead to perfection and progress, they must assume the existence of a general motivation for adaptation that cannot be verified. Competition could be another concept for explaining social evolution. Giddens refuses to accept this because it would favor war as a mechanism of social evolution which would also be a distorting simplification. Giddens thus concludes that social change cannot be traced back to the working of a unified and comprehensive social mechanism.

"In explaining social change no single and sovereign mechanism can be specified; there are no keys that will unlock the mysteries of human social development, reducing them to a unitary formula, or that will account for the major transitions between societal types in such a way either." (Giddens 1984: 243)

\section{Evolutionary theory and the comparative method}

Comparative studies may put together and structure empirical historical facts according to the needs of evolutionary theory. The comparative method is such a specific tool that translates theoretical constructs into descriptive and explanatory theories of historical change. For Nisbet the most important defect of the method is that it supports the concept of social progress that is defined as a historical process leading to Western-type societies. The comparative method defines the specific developmental characteristics of Western societies as the general criteria for classifying the cultures and societies of the world (Nisbet 1969: 190-191). The comparative method is built on a circular reasoning. It should deliver empirical proofs for the basic tenet of evolutionary theory that describes social development as a unified process that assumes the form of the social progress of consecutive and well-defined social stages. However, the comparative method presumes the concept of social progress that it is supposed to prove (Nisbet 1969: 208).14

14 Mandelbaum also argues that the comparative method justifies a conceptual scheme of development that is constructed by itself and is not related to real historical processes (Mandelbaum 1971: 125). 


\section{CRITICISM OF THE CRITICISM OF EVOLUTIONARY THEORY}

Radical criticism of evolutionary theory rejects the concept of social evolution based on the identification of evolution and progress. Moderate criticism of evolutionary theory denies the notion of social progress and argues that the theory of social evolution can be saved if we separate it from the idea of social progress. Social progress does not exist: social evolution may. I propose, and turn now to, a criticism of the moderate criticism of evolutionary theory. This criticism of the criticism of evolutionary theory seeks to uphold the possibility of an evolutionary theory of social change that remains linked to the concept of social progress not as it was done in the theories of nineteenth century, but in a modified form.

The starting point for this argument is the analytical separation of the two meanings of the concept of evolution. This distinction has already been made in the moderate criticism of evolutionary theory. Mandelbaum argued that the dual concept of evolution can also be found in Darwin's theory. On the Origin of Species offers a theory about the differentiation of species that can be understood as a history of the species without the concept of progress, but can also be read as a history of living creatures that leads to increasingly developed species (Mandelbaum 1971: 81). Evolutionary theory may give an explanation of how different living entities come into existence from one another in the process of adaptation to their environment, and evolutionary theory may also put the units of analysis into a developmental order, attributing a direction to change that leads from the less to the more developed.

"There are, however, two different ways of regarding evolutionary change. One is to regard it as a sum of successive, individual changes, where the pattern which one can retrospectively trace is regarded as being adequately explained as due to specific conjunctions of events at successive points in time. On such a view, evolutionary change is not a function of some inherent tendency for events to succeed one another in any particular pattern... On the other hand, it is also possible, in looking back on an evolutionary development, to interpret it as having had, from the outset, a tendency to move in one direction rather than another. Once such a morphic tendency is assumed, and a particular course of development is expected, change in that direction is taken as progressive, whereas an absence of change, or changes occurring in other directions, are considered as instances of stagnation, of retrogression, or as having been, in one way or another, aberrant... 
In fact, it is probably not misleading to say that there always exists a tension between these two ways of viewing a historical process. On the one hand, that which is an object of historical investigation may be regarded as constituting a whole only to the extent to which there existed a particular sequence of events which were causally related; or, on the other hand, such a process may be regarded as a whole which dominates its parts, tending to control what can affect it or what can become a part of it." (Mandelbaum 1971: 109)

Mandelbaum focuses on the tensions between these two approaches. He says that the second theory contains in itself the first one, but also that it distorts it, because it forces the specific concepts about change into a general developmental scheme. This is why the two aspects of evolutionary theory have to be separated. There is no need for the concept of progress, but the theory of evolution does not need it either. It can be sustained without it. Social progress does not exist, but social evolution does. Social evolution involves a process of social change that leads to the emergence of different configurations of different social institutions.

The critics of the moderate criticism of evolutionary theory argue that we do not have to abandon the idea of social progress. The theory of social evolution can be connected to the concept of social progress. However, in the light of the criticism of evolutionary theory this linkage has to be reinterpreted and redefined. This redefinition starts with a new distinction between two kinds of evolutionary theory. Sahlins (1960) proposed a distinction and separation between the theories of specific and general evolution. The theory of general evolution linked to the concept of social progress may not harm the examination of specific evolutionary processes if the two theories are kept separate. Also, in this case the theory of specific evolution does not discard the theory of general evolution.

It appears almost obvious upon stating it that in both its biological and cultural spheres evolution moves simultaneously in two directions. On one side, it creates diversity through adaptive modification: new forms differentiate from old. On the other side, evolution generates progress: higher forms arise from, and surpass, lower. The first of these directions is Specific Evolution, and the second, General Evolution. But note that specific and general evolution are not different concrete realities; they are rather aspects of the same total process, which is also to say, two contexts in which we may place the same evolutionary things and events. Any given change in a form of life or culture can be viewed either in the perspective of adaptation or from the point of view of overall progress. 
However, the context is very important: a difference in taxonomy is required in examining these two aspects of evolution. Concerned with lines of descent, the study of specific evolution employs phylogenetic classification. In the general evolutionary outlook emphasis shifts to the character of progress itself, and forms are classed in stages or levels of development without reference to phylogeny (Sahlins 1960: 12-13).

Where Mandelbaum sees tension, Sahlins finds a unity of theories. On the basis of his proposition, the idea of social progress can be saved and remains linked to evolutionary theory; that is, to general evolutionary theory. The distinction between the general and specific theory of evolution is not based on that of an analytical model versus empirical reality. The model of general evolutionary theory does have a realistic and therefore temporal dimension. General evolutionary theory articulates the analytical structure of the temporal dimension by tying the concept of social progress to the dichotomy of traditional versus modern society. In general evolutionary theory, social progress is also understood as the transition from traditional to modern society. Therefore general evolutionary theory has a historical and empirical relevance that should be identified and discovered via the assistance of the specific evolutionary theory related to the analysis of particular societies. The notion of progress defined in general evolutionary theory should be applied by the specific evolutionary theory that deals with particular societies. Social progress defined by general evolutionary theory in terms of stages or levels of social development will inform specific evolutionary theory that deals with particular societies and specific historical pathways of social change. To give an example, general evolutionary theory spells out the main characteristics of modernity contrasted with traditional social order. It argues that modernity represents social progress in contrast with traditional social order from a certain perspective that should be well-defined within and by the general theory. Specific evolutionary theory explains why modernity came first into existence in Western Europe and not elsewhere. Both theories have an analytical and a historical dimension but in a different way. From this it follows that we have to rethink and re-examine the arguments made by the critics of evolutionary theory to find out whether the proposition about the connection of social progress and evolutionary theory may be validated. This is the task I now turn to. 


\section{Societies can be ordered in a developmental sequence}

Critics of evolutionary theory argue that the theory projects an artificial analytical construct of a developmental sequence on historical reality, and therefore misses the opportunity to understand the specific historical causes of social change. It is true that the evolutionary sequence of social development is an analytical construct. However, this does not mean that it is wrong, unrealistic, or useless. ${ }^{15}$ The merit of the criticism of evolutionary theory is that it calls attention to the limits of the application of the analytical schemes of evolutionary theory. However, it goes too far if it claims evolutionary theory unscientific and meaningless just because it tries to attribute to and understand the logical structure of social development.

The theory of social evolution is not and cannot be a causal theory of specific changes in and of societies. This is a limitation on the theory that should be taken seriously. However, accepting the distinction between the specifichistorical and the universal-analytical levels of explanation, the critics of the anti-evolutionary approach turn the tables and argue that the investigation of social change should not be reduced to a causal explanation of individual and historical events and relationships. The evolutionary approach is more complex than its criticism because it does not deny the possibility of a general theory, while it also accepts the existence of the level of specific-historical analysis. ${ }^{16}$

15 Moderate critics of evolutionary theory also agree. "As soon as we consider theories of social change as ideal constructs we need no longer be surprised and worried by the fact that some social systems follow such-and-such theory, while others - though they are apparently very comparable - do not. All this does not maintain that these theories are useless, since they can eventually be applied to some social systems and can be taken as guides for the understanding of others." (Boudon 1983: 157) "The theories of change are interesting provided that they are taken as mental constructs whose adequacy to reality is conditional and can only be demonstrated a posteriori." (Boudon 1983: 158)

16 "What distinguishes an evolutionary perspective is not its refusal to recognize and appreciate the historically unique. Rather, it is its refusal to believe that the historically unique is of greater intellectual significance than the historically general. Evolutionists do not use their concern with the general to deny the particular. Particularists, however, do use the particular to deny the general, and it is this - not the existence or importance of the particular per se - that constitutes the rub for social evolutionists." (Sanderson 1990: 219) 


\section{The understanding of social change needs universal concepts that are not timeless}

Historical change cannot be described by historically invariant concepts, say critics. This argument contains two elements: (1) a methodological skepticism about the chance of grasping specific empirical data about social change with universal concepts, and; (2) the assumption that social change does not create invariant social institutions that remain sustainable in time.

Methodological skepticism seems to be present in Nisbet's criticism of the theory of social evolution. He says that "the more concrete, empirical, and behavioral our subject matter, the less the applicability to it of the theory of development and its several conceptual elements" (Nisbet 1969: 267). For Nisbet, the theory of social progress or social evolution is an analytical construct that has nothing to do with the study of history. ${ }^{17}$ Methodological skepticism has a long history in philosophy - let me only refer to the early controversy between nominalism and realism or between empiricism and rationalism. This dichotomy was translated into the dichotomy of natural sciences versus social sciences, within neo-Kantianism into the dichotomy of nomothetic versus idiographic sciences. Within this framework the argument was made that only natural sciences can formulate universal concepts, while social sciences are limited to the study of historical and therefore individual phenomena. In this paper I do not deal with these highly complex methodological issues and their history.

Point (2) is open to criticism. If social change creates and sustains institutions - elements that remain invariant in time - these historical invariants can be analyzed using general concepts. Also, general concepts as ideal types may be able to classify and categorize historical processes (Boudon 1983: 157). The evolutionary approach of social change is dependent on invariant concepts.

The understanding of historical change is built on the historical application of invariant, functional relationships (Mandelbaum 1971: 120-126). The basic categories of evolutionary theory like variation, selection, and stabilization can be considered invariants. Invariance does not refer to the content of these categories, but to the role they play in theory. They serve as a conceptual framework of social change that sustains change. The content of each category may change: variability may mean different units and traits that emerge in time; selection criteria may also change and the objects of stabilization will also be

17 "...whatever might be the value of the theory of progressive development in the study of mankind in the large, for the study of history it was valueless: history in the sense of the concrete, the particular, and the temporal." (Nisbet 1969: 268) 
different. "...the principles governing the evolutionary process are, themselves, subject to evolutionary change...." (Lenski 1976: 559).

The distinction between traditional and modern societies means that social change follows different regulatory principles in traditional than in modern societies. In the evolutionary process of transition from traditional to modern society, new institutions and social relations of a market society emerge. These new social institutions, like money, market, representative political democracy are able to stabilize themselves in time. As a consequence, they become from the object of social change into a framework of social change. Social change does not consume these institutions but takes place within them, therefore further cumulative changes in production, technologies, science, etc. do not eliminate but preserve them. In other words, the new social institutions of market society (capitalism) are able to absorb social change, instead of opposing and constraining it. Parsons called these invariant social institutions that are the products of social evolution evolutionary universals. ${ }^{18}$ Among others, money, the market, bureaucratic organization and political democracy - that is, the basic institutions of modern capitalist society - are such evolutionary universals (Parsons 1967). Invariance does not mean that they do not change any more. For instance, money has assumed different forms in modern capitalism, but it has nonetheless remained money. What is implied by the notion of invariance it is that evolutionary universals create a complex of institutions in modern society that due to its enhanced adaptive capabilities is able to reproduce itself in time. The disappearance of evolutionary universals would mean devolution and the loss of those achievements that are tied to these evolutionary universals that constitute the basic institutions of modern societies. This is the real meaning of the concept of end of history. ${ }^{19}$ Obviously, history never stops, but history may either change institutions or may reinforce institutions.

18 "I shall designate as an evolutionary universal any organizational development sufficiently important to further evolution that, rather than emerging only once, it is likely to be 'hit upon' by various systems operating under different conditions." (Parsons 1967: 49)

19 The concept of end of history was popularized by Fukuyama: "Both Hegel and Marx believed that the evolution of human societies was not open-ended, but would end when mankind had achieved a form of society that satisfied its deepest and most fundamental longings. Both thinkers thus posited an "end of history": for Hegel this was the liberal state, while for Marx it was a communist society.... It meant... that there would be no further progress in the development of underlying principles and institutions, because all of the really big questions had been settled." (Fukuyama 1992: XII) 


\section{Social change may have a direction}

The idea of progress assumes a chosen criterion of development. Societies can be ordered into a developmental sequence on the basis of these criteria. The critics of evolutionary theory consider these criteria to be arbitrary in relationship to social change. They say that these developmental criteria are imposed on history by the representatives of evolutionary theory and simply reflect the values of scholars dealing with the problems of social change.

The critics of this criticism argue that the idea of cumulative change (that is, progress) is not arbitrary but a trend that takes shape in social change. ${ }^{20}$ Cumulative change does exist in the history of societies. However, the criteria of progress are different. Depending on the selection of the criteria, different authors have defined social evolution as a progressive process of social change in different ways. Spencer wrote about changes in social differentiation ${ }^{21}$, Marx about the unfolding of the human capacity of universal production ${ }^{22}$, Luhmann about the growing differentiation of social systems ${ }^{23}$, Habermas about the

20 In contrast to Nisbet Lenski shows that the claims of neo-evolutionary theory "of growth in human population, in the permanence of settlements, in the size and complexity of societies, in the degree of urbanization, in the extent of the division of labor, in social inequality, in the mobilization of energy, in the production of goods and services, in accumulated wealth, and, above all, in information are firmly grounded in the historical record. They do not depend on the logic of metaphor or analogy, and to imagine that they do is to misperceive the situation." (Lenski 1976: 561-562)

21 "Evolution is an integration of matter and concomitant dissipation of motion; during which the matter passes from an indefinite, incoherent homogeneity to a definite, coherent heterogeneity..." (Spencer 1897: 407)

22 "Universally developed individuals, whose social relations, as their own communal [gemeinschaftlich] relations, are hence also subordinated to their own communal control, are no product of nature, but of history. The degree and the universality of the development of wealth where this individuality becomes possible supposes production on the basis of exchange values as a prior condition, whose universality produces not only the alienation of the individual from himself and from others, but also the universality and the comprehensiveness of his relations and capacities." (Marx 1993: 162)

23 "Statt als einheitlicher Kausalprozeß ist Evolution zu begreifen als eine Form der Veränderungen von Systemen, die darinbesteht, daß Funktionen der Variation, der Selektion und der Stabilisierung differenziert, das heißt durch verschiedene Medianismen wahrgenommen, und dann wieder kombiniert werden” (Luhmann 1976: 286). “....läßt sich zeigen und historisch belegen, daß es im Fortschreiten der gesellschaftlichen Entwicklung zu stärkerer funktionaler Differenzierung nicht beliebig zugeht." (Luhmann 1976: 291) 
separation of systems and a rationalized life world ${ }^{24}$, White about the growth in the capacity of societies to utilize energy, ${ }^{25}$ etc.

These standards can be divided into two groups. The first group contains standards related to science and technology, to the metabolic interaction of society with nature, to the development of production. The second group contains standards related to the development of social institutions (differentiation and complexity of social institutions). The first group of standards register changes that can be expressed quantitatively and measured as different stages of a continuous and cumulative process. The second group of standards creates a developmental sequence on the basis of qualitative and punctuated changes and identifies stages of development that represent different configurations of social institutions and orders as different social forms. These two types of standards are not independent from each other. If social progress means a cumulative substantive process that can be quantitatively measured, a society will be more developed that ranks higher on a scale that measures accumulated knowledge or the level of technological development or the amount of accumulated wealth or an increased capacity to produce more.

If we ask the question what explains the differences on these scales among societies, we arrive at standards of the second type, since we will relate them to the differences in the configuration of social institutions. Basically, the argument is that institutional configurations of traditional societies put limitations on the social capacities of these societies to know more, to produce more, etc. On the other hand, institutional configurations of modern (that is, capitalist) societies remove these limitations.

This explanation should not be understood as an attempt to build a multi-level stage theory, because the application of the first standard shows a tendency to non-linear development - human history testifies about progress and regress in that respect. Consequently, there has been no linear development from

24 "I understand social evolution as a second-order process of differentiation: system and life world are differentiated in the sense that the complexity of the one and the rationality of the other grow" (Habermas: 1987: 153).

25 "From a zoological standpoint, culture is but a means of carrying on the life process of a particular species. Homo sapiens. It is a mechanism for providing man with subsistence, protection, offense and defense, social regulation, cosmic adjustment, and recreation. But to serve these needs of man energy is required. It becomes the primary function of culture, therefore, to harness and control energy so that it may be put to work in man's service. Culture thus confronts us as an elaborate thermodynamic, mechanical system. By means of technological instruments energy is harnessed and put to work. Social and philosophic systems are both adjuncts and expressions of this technologic process. The functioning of culture as a whole therefore rests upon and is determined by the amount of energy harnessed and by the way in which it is put to work." (White 1949: 367-368) 
early communal societies through antiquity and feudalism to capitalism. Early feudalism as a successor of antique society was a regression from an economic perspective. Instead, this explanation introduces a dichotomy between traditional and modern (capitalist) society and argues that within this dichotomy modernity represents social progress in the light of cumulative developments in science, in technology and in the economy. This cumulative development was made possible by that historical process that led to the formation of capitalist (or market) society, since the new institutional configuration of modernity based on the separation of the private and public sphere of society set free those human energies that led to cumulative development in science, technology and economy in the first place.

In the language of macrosocial theory, modern society could come into existence on the basis of the separation of social and system integration. ${ }^{26} \mathrm{In}$ traditional societies, the possibility of impersonal exchange ${ }^{27}$ was limited by the imperatives of social integration. In modern society impersonal exchange could develop because it was decoupled from social integration and relied on its own mechanism of system integration that economists call market coordination. On this basis we can talk about social progress. This theory says that modern society will be ranked at the top for development both on the first and second types of scales.

This is the reason why the idea of social progress concerns the dichotomy of modern versus traditional society. ${ }^{28}$ Therefore, the defense of this idea means the justification of this dichotomy that is present in sociology, in economic theory, in political science. In this paper I deal only with sociological theory.

Critics of evolutionary theory argue that on the basis of the traditional-modern dichotomy the idea of social progress maintains the apology of modernity; does not make it possible to understand the existence or the dissolution of traditional

26 On this separation, see Habermas (1987).

27 North argues that impersonal exchange is a major source of economic wealth: "In fact, most societies throughout history got "stuck" in an institutional matrix that did not evolve into the impersonal exchange essential to capturing the productivity gains that came from the specialization and division of labor that have produced the Wealth of Nations." (North 1994: 364)

28 The importance of this dichotomy is accepted also by Giddens who otherwise is a critic of evolutionary theories: "Rather than seeing the modern world as a further accentuation of conditions that existed in class-divided societies, it is much more illuminating to see it as placing a caesura upon the traditional world, which it seems irretrievably to corrode and destroy. The modern world is born out of discontinuity with what went before rather than continuity with it. It is the nature of this discontinuity - the specificity of the world ushered in by the advent of industrial capitalism, originally located and founded in the West - which it is the business of sociology to explain as best it can." (Giddens 1984: 239) 
societies; omits the negative effects and consequences of modernity and modernization from theoretical analysis.

It is true that the concept of social progress is value-bound. However, the application of value to a historical process for the measurement of cumulative development only means that from the perspective of the chosen value historical change can be treated as a cumulative process. If we chose a different value we arrive at a different conclusion. For instance, we may find that modernity creates a cumulative development of science and also undermines moral values. If evolutionary theory argues that modern (capitalist) society is superior to traditional societies, it also has to deal with the issue of trade-offs.

Modernity leads to economic wealth and technological progress just because it is able to separate system integration (market coordination) from social integration (moral values of the community). For the increase in adaptive capabilities, modern society pays with the weakening of commitment to moral values. Can we say that the increase is greater than the loss? This question implies that different dimensions of social systems can be homogenized to the extent that the loss of social integration can be detracted from the gain stemming from system integration. Collingwood is right in making the point that this cannot be done.

If thought in its first phase, after solving the initial problems of that phase, is then, through solving these, brought up against others which defeat it; and if the second solves these further problems without losing its hold on the solution of the first, so that there is gain without any corresponding loss, then there is progress. And there can be progress on no other terms. If there is any loss, the problem of setting loss against gain is insoluble. (Collingwood 2005: 329)

How can the idea of social progress be saved if progress in one social domain is linked to regress in another? The concept of social progress may make sense only if it is limited to those social spheres where cumulative development does happen. Social progress cannot be understood as a general process of the perfection of society. Lenski is right to say that the idea of social progress does not mean that modern society is in general superior to traditional societies. ${ }^{29}$

29 "In the older evolutionism there was a pervasive tendency to see progress on almost every front, from the technological to the moral. Human life was thought to be growing better in almost every possible way. Contemporary evolutionists do not share this optimism. When they use the term 'progress,' they use it only to call attention to specific directional trends... I think there is a growing tendency among evolutionists to define sociocultural evolution as growth in the store of symbolically coded information and its consequences. Such a definition has no built-in assumptions about moral progress or any other form of human betterment: these remain empirical questions." (Lenski 1976: 561) 
This distinction enables the theory to integrate and deal with the negative effects of a cumulative social process. These negative effects can be understood as the price society has to pay for cumulative development. This is the interpretation of social progress we can find in Habermas' social theory. On the basis of the conceptual distinction of system and life world, Habermas may interpret social evolution as a process that leads to the separation of system and life world in modern society. Social evolution does constitute the separation of social systems of the economy and the polity from the social lifeworld that goes through a process of rationalization. Social systems do create cumulative development but they also try to colonize the lifeworld of society and consequently undermine social values and social integration. This theory is able to thematize the price modern society pays for social progress (Habermas 1987).

However, from the perspective of evolutionary theory it remains sensible to talk about social progress in relation to society as a specific configuration of social relations and institutions if we understand that cumulative development in the economy, science and technology makes modern societies more capable compared to traditional societies that lag behind in these terms. Since different social systems with different social institutions compete with one another within an evolutionary process, the superiority of modern societies in terms of its capabilities to mobilize material resources leads to an evolutionary process in the framework of which the more developed crowds out the less developed.

Consequently, the problem of evaluation duplicates itself. The question of the application of values chosen as standards is complemented with that of the evaluation of values as chosen standards. Next to the question whether a chosen value can really measure progress (for instance, the question about the concept of complexity), there is another one concerning why this value and not another may be a criterion of progress. The criteria of evaluation can thus be questioned. If it is understood, the concept of social progress can be distinguished from the apology of modernity. As Sanderson puts it, social progress is not the summary of human history. ${ }^{30}$

30 "If the notion of directionality is taken to refer to some sort of single master trend that alone summarizes all of human history, then it immediately loses its usefulness. Lenski himself attempts to identify such a trend, which he refers to as growth in the store of information humans have available to them. And Parsons finds a single master trend in increasing differentiation. But the notion of such a trend is too general, too abstract, to have much value. In using the notion of directionality, we must be on guard against the tendency toward a kind of simplistic unilinearism. This is a very real tendency to which the classical evolutionists were certainly subject, and toward which modern evolutionists like White, Lenski, and (especially) Parsons are also inclined. It has been said many times before, but it bears repeating that we must constantly be alert to the distinction between general and specific evolution or, in Harris's terminology, parallel, convergent, and divergent evolution.” (Sanderson 1990: 217-218) 
Critics of evolutionary theory have pointed out correctly that the concept of unilinear development cannot be accepted because by interpreting human history as the unfolding of human essence in time it imposes a teleology on the historical process. The important point is how human essence is defined. It can be tied to a substantive characteristic of human existence or to a set of social institutions. In the first case, we can find a cumulative process in history. For instance, on a general level Marx defined human essence as the capacity of humans to produce universal wealth (Marx 1992: 329). On this basis he could argue that capitalism was superior to precapitalist societies just because capitalism was able to unfold the potentiality of universal production residing in human essence. However, he also asked the question why capitalism was able to achieve what previous societies could not. In his answer he pointed out that the unfolding of human essence is linked to the emergence of a specific complex of social institutions.

Different sets of social institutions represent different qualities that cannot be interpreted from the perspective of cumulative development because this is based on a quantitative concept of comparison. For Marx, the way out of this problem was an indirect theory of social progress: societies do represent different qualities but they also represent different stages of social development because they are able to unfold the human potential of universal production to a different extent. In other words, the duality of substantive and institutional components of social change should lead to a dual theory of social evolution. Social development may realize cumulative processes but in itself it does not prescribe any specific direction of historical change since these cumulative processes do not drive social change. They are simply consequences of changes in social institutions. Marx was right in distinguishing between these two levels of analytical thinking but he was wrong in assuming an inevitable sequence of historical change in relationship to different institutional settings of societies.

\section{Social change is not inevitable}

Critics of evolutionary theory rightly say that social change is not unilinear and not inevitable. These ideas must be removed from the theory of social evolution. They also argue that, consequently, the theory of social evolution should be freed from the concept of social progress. This criticism is based on the identification of social progress and the inevitability of social change. However, social progress can be defined in a way that is free from the idea of unilinearity and inevitability of social change. Therefore, the idea of inevitability can be 
dropped and the idea of social progress can be saved. The two-level concept of social evolution does exactly this. It assumes a cumulative process of social change within the framework of general theory but leaves open the question how social progress evolves in history, and also whether it happens. ${ }^{31}$

\section{There is no unified subject of social change, but individual actors may create emergent social properties}

Critics of evolutionary theory have pointed out that the idea of social progress assumes the existence of an imaginary general subject. Social progress is related to a general social subject because social progress is seen as the consequence of social actions carried out by the general subject of history. This theory is wrong because the subject of human actions is not society, civilizations or humanity but individuals.

We can accept that only individuals act, but in their actions they may represent different social entities. In relationship to the idea of progress, the main problem is not whether we accept methodological individualism or not. ${ }^{32}$ Rather, the question is whether the concept of individual actions is compatible with the concept of social progress. I think it is. Social progress can be interpreted as the result of individual actions. Individual actions may generate emergent social qualities that may be evaluated from the perspective of being or not being able to generate a cumulative process. Social progress may be studied on the level of the social whole that goes beyond that of the individual without making the assumption that it is created by the social entity as an actor. After all, it is the main tenet of evolutionary theory that individual actors create social relations

31 "One of the important differences between the 19th- and 20th century forms of evolutionism is the shift from deterministic to probabilistic formulations." (Lenski 1976: 557)

32 Interestingly, Sanderson accepts methodological individualism and criticizes functional system theory in order to defend evolutionary theory. "The evolutionary theories of Parsons and Leslie White may be taken as exemplifications of the most extreme objectivist forms of evolutionism. The entire corpus of Parsons's social theory rests upon a horrendously reified social system in which individual actors are but 'carriers' or 'bearers' of the properties of the system. This reified view of social life is thoroughly present, of course, in his evolutionism. It is societies that differentiate, adapt, and have identities of themselves. If ever an evolutionism was an extreme objectivism, Parsonian evolutionism is it." (Sanderson 1990: 213) "...make the individual, rather than some abstract social system, the unit of adaptation and thus assume that evolutionary events are somehow rooted in the cost-benefit calculations of individuals caught up in particular circumstances...” (Sanderson 1990: 224) 
and emergent social properties that they did not intend to create. Social evolution comes about as an unintended consequence of human action. ${ }^{33}$

\section{Adaptation helps to explain social change}

The concept of adaptation is tautological; it does not provide the microfoundations of individual actions and a causal explanation of the emergence of social institutions, therefore it has to be rejected, argues Giddens.

It is correct to say that the adaptation of society to its environment concerns a functional relationship that also needs to be explained. Therefore, it does not offer a causal explanation of social change. The emergence of social institutions cannot be deduced from their functions. However, when we compare different societies we pay attention to the differences in adaptations societies are capable of. Differences in adaptation will reveal differences in the capabilities of societies to mobilize material resources. This is important because societies compete with one another under the pressure of social selection. The adaptation of societies takes place not just against their natural environment but also against other societies that also constitute their environment.

Giddens thinks that extending the concept of adaptation makes it empty and takes away its explanatory power. However, if the concept of adaptation is not considered to be part of a causal explanation it remains important and useful because by measuring the performance of different societies it makes it possible to rank them, and helps understand their evolutionary success or failure that is also important for a causal explanation. ${ }^{34}$

33 “...see evolutionary events as the product of human agency, while recognizing that much of what happens in these events is different from, or even contradictory to, human intentions; in other words, a good evolutionary theory takes seriously Giddens's notion of the duality of structure in social life." (Sanderson 1990: 224)

34 As opposed to Giddens, Sanderson also thinks that the concept of adaptation makes sense for evolutionary theory. However, for him this is the case only if we separate the concept of adaptation from functional explanations. For Sanderson it follows from his choice of and support for methodological individualism. "Adaptation is a process pertaining to individuals, and not to any social unit higher than the individual." (Sanderson 1990: 188) 


\section{The comparative method helps to explain social change}

Critics of evolutionary theory argue that the comparative method leads to circular reasoning and cannot prove the existence of social progress. However, in the use of the comparative method circular reasoning may be avoided. The comparative method can mediate between the general and specific theory of evolution. On the basis of a general theory of evolution the comparative method can be embedded in the distinction of traditional versus modern society. General theory provides those criteria that lead to the construction of the models of these two (traditional versus modern) societies. Then the comparative method helps to describe existing historical societies in relationship to these models. This way the comparative method also helps to raise questions about the specific historical trajectories of particular societies. In doing all this the comparative method does not offer a causal explanation and empirical confirmation of the general theory, but rather applies it to the analysis of different and particular societies. Consequently, the comparative method is useful for understanding the processes of specific evolution and for assessing and evaluating empirical material about the evolutionary capabilities and performance of different societies and also their historical emergence. There is no need to reject the comparative method (Sanderson 1990: 212).

\section{CONCLUSION}

The criticism of early evolutionary theories of society revealed the weaknesses of these theories but went too far. The idea of social progress was the main target of this criticism. Anti-evolutionary theories were intended to justify the separation of the concepts of social change and cumulative development. I do not think that these theories carried out the decoupling of social evolution and social progress in a successful and analytically compelling way. I have argued that, although the criticism of evolutionary theory should be taken seriously, the concept of social progress as processes of cumulative development within society does not have to be abandoned and may be preserved, if in a limited and newly defined way. ${ }^{35}$

Social progress can be understood as a cumulative process of enhancing the adaptive capabilities of societies. It should be a descriptive concept that can

35 Sanderson's Evolutionism and Its Critics also argues against the separation of the concept of social progress and that of social evolution (Sanderson 2007: IX., 256-257). 
be evaluated either positively or negatively; this evaluation is not an intrinsic feature of the concept. Social progress does not mean the increasing perfection of societies in general but an enhanced capability to be successful through the competition of social forms that represent different configurations of social institutions. Table 1 summarizes the argument.

\section{Table 1. Anti-evolutionism versus neo-evolutionism}

\begin{tabular}{|c|c|}
\hline Anti-evolutionism & Criticism of anti-evolutionism \\
\hline $\begin{array}{l}\text { The theory of social evolution is an analytical } \\
\text { construction that does not explain the historical } \\
\text { change of societies and imposes a scheme of } \\
\text { the theory of stages on it }\end{array}$ & $\begin{array}{l}\text { Evolutionary theory is an analytical construction } \\
\text { but it does not aim at giving specific explanations } \\
\text { of historical changes of societies, rather it seeks } \\
\text { to discover the cumulative processes behind } \\
\text { these changes. Evolutionary theory is not a } \\
\text { theory of social stages }\end{array}$ \\
\hline $\begin{array}{l}\text { The idea of social progress relies on standards } \\
\text { that are arbitrary and does not reflect historical } \\
\text { changes; these are imposed on history from } \\
\text { outside by scholars who derive such standards } \\
\text { from their values }\end{array}$ & $\begin{array}{l}\text { If there is cumulative development in history, } \\
\text { its standard cannot be arbitrary. Any standard } \\
\text { can be reflected on. The idea of cumulative } \\
\text { development does not imply that social change } \\
\text { is cumulative in all its elements }\end{array}$ \\
\hline $\begin{array}{l}\text { The theory of social evolution, by positing } \\
\text { the dichotomy of traditional versus modern } \\
\text { society, becomes an ideological construction } \\
\text { that serves as the apology of Western societies }\end{array}$ & $\begin{array}{l}\text { The contrast between traditional and modern } \\
\text { society is based on real historical processes. The } \\
\text { evolutionary theory of social progress has also } \\
\text { to integrate and deal with problems that emerge } \\
\text { as the price of development. Consequently, the } \\
\text { apology of modern society can be avoided }\end{array}$ \\
\hline $\begin{array}{l}\text { The theory of social evolution that is } \\
\text { built on the idea of social progress is non- } \\
\text { scientific because it assumes a teleological, } \\
\text { endogenous, unilinear and inevitable process } \\
\text { of development }\end{array}$ & $\begin{array}{l}\text { The idea of progress has to be separated } \\
\text { from the idea of a teleological, unilinear and } \\
\text { inevitable development }\end{array}$ \\
\hline $\begin{array}{l}\text { The idea of social progress presumes the } \\
\text { existence of a general and imaginary subject } \\
\text { of action }\end{array}$ & $\begin{array}{l}\text { The idea of social progress does not imply } \\
\text { the existence of a general subject of action. } \\
\text { It is individuals who act, but they may } \\
\text { create emergent social properties and social } \\
\text { relationships that go beyond them }\end{array}$ \\
\hline $\begin{array}{l}\text { The theory of social evolution does not identify } \\
\text { the mechanism of evolution. The concept of } \\
\text { adaptation cannot provide this mechanism } \\
\text { because it is a tautological and empty concept }\end{array}$ & $\begin{array}{l}\text { The concept of adaptation if it is related to the } \\
\text { adaptation of social institutions is useful for } \\
\text { measuring the evolutionary performance of } \\
\text { societies }\end{array}$ \\
\hline $\begin{array}{l}\text { The comparative method does not prove the } \\
\text { theory of social evolution because it is trapped } \\
\text { in a circular argument }\end{array}$ & $\begin{array}{l}\text { The comparative method can be useful in the } \\
\text { theory of specific evolution and for identifying } \\
\text { the differences of capabilities of societies }\end{array}$ \\
\hline
\end{tabular}


The paradigm of evolutionary theory of societies contains three major elements: (1) Social change may be cumulative and directional; (2) the cumulative processes of development can be traced back to the existence and working of social institutions, and; (3) social evolution and social progress are the unintended consequences of human action. ${ }^{36}$ Anti-evolutionary criticism accepts Point (3) but rejects Point (1) and remains silent about Point (2) because it disconnects the concept of social progress from that of social change. I have argued that on the basis of the distinction between general and specific evolution one has to treat all three points as inter-related. They assume each other. Cumulative social development is the result of the historical process of selection of social institutions. The evolution of social institutions and the performance of societies is an outcome that can be understood as the unintended consequence of human action, something that is done but not intended by the acting individuals.

\section{REFERENCES}

Boudon, Raymond (1983) 'Why Theories of Social Change Fail: Some Methodological

Thoughts' Public Opinion Quarterly, 47(2):143-160. https://doi. org/10.1086/268778

Collingwood, Robin George (2005) The Idea of History. New York: Oxford University Press.

Fukuyama, Francis (1992) The End of History and the Last Man. New York: The Free Press.

Giddens, Anthony (1984) The Constitution of Society. Outline of the Theory of Structuration. Cambridge: Polity Press.

Giddens, Anthony (1981) A Contemporary Critique of Historical Materialism. Power, property and the state. Vol. 1, London: Macmillan and Basingstoke.

Habermas, Jürgen (1987) The Theory of Communicative Action. Vol 2, Boston: Beacon Press.

Lenski, Gerhard (1976) 'History and Social Change' American Journal of Sociology, 82 (3): 548-564. https://doi.org/10.1086/226353

Luhmann, Niklas (1976) 'Evolution und Geschichte' Geschichte und Gesellschaft, 2(3): 284-309.

Mandelbaum, Maurice (1971) History, Man, \& Reason. A Study in Nineteenth Century Thought. Baltimore and London: The John Hopkins University Press.

36 This point is also emphasized by Sanderson (2007: 301).

CORVINUS JOURNAL OF SOCIOLOGY AND SOCIAL POLICY VOL. 9 (2018) 1 
Marx, Karl (1992) Early Writings. London: Penguin Books in association with New Left Review.

Marx, Karl (1993) Grundrisse. Foundations of the Critique of Political Economy (Rough Draft). London: Penguin Books.

Nisbet, Robert A. (1969) Social Change and History. Aspects of the Western Theory of Development. New York: Oxford University Press.

North, Douglass C. (1994) 'Economic Performance Through Time' The American Economic Review, 84(3): 359-368.

Parsons, Talcott (1967) 'Evolutionary Universals in Society' In: Parsons, T.: Sociological Theory and Modern Society. New York: The Free Press, 490520.

Sahlins, Marshall D. (1960) 'Evolution: Specific and General' In: Sahlins, Marshall D - Service, Elman R. (eds.) Evolution and Culture. Ann Arbor: University of Michigan Press, 12-44.

Sanderson, Stephen K. (1990) Social Evolutionism. A Critical History. Cambridge and Oxford: Basil Blackwell.

Sanderson, Stephen K. (2007) Evolutionism and Its Critics: Deconstructing and Reconstructing an Evolutionary Interpretation of Human Society. London and New York: Routledge.

Spencer, Herbert (1897) First Principles. New York: D. Appleton and Company. Sárkány, Mihály - Somlai, Péter (2003) 'A haladástól a kontingenciáig. Vázlat a szocio-kulturális evolúció változó elméleteiről.' Szociológiai Szemle, 3: 3-26. White, Leslie A. (1949) The Science of Culture. New York: Grove Press. 
